\title{
Effect of Plant-Growth-Promoting Fungi on Eggplant (Solanum melongena L.) in New Reclamation Land
}

\author{
Xuqing $\mathrm{Li}^{1}{ }^{1}$, Dingyi $\mathrm{Li}^{2}$, Jianli Yan ${ }^{1, *}$, Ya Zhang ${ }^{1}$, Hong Wang ${ }^{1}$, Jingze Zhang ${ }^{3, *} \mathbb{C}$, Temoor Ahmed ${ }^{3}$ and Bin $\mathrm{Li}^{3} \mathbb{1}$ \\ 1 Institute of Vegetable, Hangzhou Academy of Agricultural Science, Hangzhou 310024, China; \\ lixqing@hz.cn (X.L.); zhangyaae@gmail.com (Y.Z.); hnwanghong123@gmail.com (H.W.) \\ 2 Department of Biological Environment, Material and Environmental College, \\ Shanxi Jinzhong Institute of Technology, Jinzhong 030600, China; wangdc@hz.cn \\ 3 Institute of Biotechnology, College of Agriculture and Biotechnology, Zhejiang University, Hangzhou 310058, \\ China; temoorahmed@zju.edu.cn (T.A.); libin0571@zju.edu.cn (B.L.) \\ * Correspondence: yanjianli00@gmail.com (J.Y.); jzzhang@zju.edu.cn (J.Z.)
}

Citation: Li, X.; Li, D.; Yan, J.; Zhang, Y.; Wang, H.; Zhang, J.; Ahmed, T.; Li, B. Effect of Plant-Growth-Promoting Fungi on Eggplant (Solanum melongena L.) in New Reclamation Land. Agriculture 2021, 11, 1036. https://doi.org/10.3390/agriculture 11111036

Academic Editors: Tibor Szili-Kovács and Tünde Takács

Received: 15 September 2021

Accepted: 19 October 2021

Published: 22 October 2021

Publisher's Note: MDPI stays neutral with regard to jurisdictional claims in published maps and institutional affiliations.

Copyright: (c) 2021 by the authors. Licensee MDPI, Basel, Switzerland. This article is an open access article distributed under the terms and conditions of the Creative Commons Attribution (CC BY) license (https:// creativecommons.org/licenses/by/ $4.0 /)$.
Abstract: Land reclamation may expand the supply of usable land for food security. Immature soil is not suitable for plant growth and needs to be amended by the addition of organic matter and plant growth-promoting (PGP) microorganisms. However, the effects of different PGP fungi on plant growth in immature soil are largely unexplored. In order to obtain beneficial soil microorganisms with a good PGP ability in new reclamation land, 162 fungal isolates were isolated from different abandoned wastelands, four isolates of which were obtained in this study by the screening of $\mathrm{P}$ solubilization, siderophore production, and indole acetic acid (IAA) production. The result of this study revealed that isolate HZ123 had the highest ability to solubilize P and produce siderophores and IAA, followed by HZ23, HZ10, and HZ06. Based on the results of morphological and molecular analyses, isolate HZ06 was identified as Penicillium oxalicum, isolates HZ23 and HZ10 were identified as Aspergillus brunneoviolaceus, and isolate HZ123 was identified as Aspergillus tubingensis. Furthermore, the results of in vivo PGP assays demonstrated that isolate HZ123 has a minimal negative effect on the growth of eggplant; however, the other three isolates, particularly isolate HZ06, caused the greatest increase in eggplant biomasses. Overall, these results indicate that isolate HZ06 has great potential as a PGP fungus to develop biofertilizer for application in eggplant production in immature soil from new reclamation land.

Keywords: soil amendment; phylogenetic analysis; Penicillium; Aspergillus; immature soil

\section{Introduction}

China is the world's most populous country, and, as such, food security is a huge problem currently facing the country. With the development of urbanization and the decrease in available land resources, expanding the utilization of land resources has become an important task to ensure food security in Hangzhou city, Zhejiang province, China. In order to expand the available land supply, the barren mountain land and forest land in the mountainous areas of Hangzhou, Zhejiang Province, China, were reclaimed for agricultural use. The immature soil in developed land is not suitable for plant growth because it does not have enough time to develop via normal soil-forming processes. In most instances, the soil is acidic and poor in nutrients with a high gravel content [1].

In recent years, eggplant cultivation in mountainous areas has been well developed in Zhejiang Province, especially in Hangzhou, due to its various advantages. During the growth of eggplant, organic amendments, such as livestock manure, biosolids, pulp byproducts, wood residuals, and crop residues, are widely used in soil reclamation, which can modify soil physical and chemical properties and exert a great influence on heterotrophic microbial communities [2]. Moreover, soil microorganisms have played an important role 
in the formation and evolution of soil ecosystems, while some species of bacteria and fungi can contribute to nutrient bioavailability and aggregate formation in soils [3].

In agricultural soils, plant growth-promoting (PGP) microorganisms as inoculants can enhance plant growth and abiotic stresses through a wide variety of mechanisms [4]. PGP fungi constitute different genera of nonpathogenic fungi that provide various benefits to their host plants, such as altered soil chemistry, altered microbial communities, and improved biomass [5]. The mechanisms of PGP fungi may be attributed to phosphate solubilization [6,7], the production of siderophores [8], the production of extracellular enzymes and indoleacetic acid (IAA) [9], the production of volatile organic compounds [10], the suppression of plant pathogens, and amelioration of abiotic stresses [11]. However, little information is available on theveffect of PGP fungi on plant growth in immature soil.

We hypothesize that the PGP microorganisms from immature soil have a good ability to survive in new reclamation land. Thus, the aim of this study was to screen native isolates of fungi from the immature soil of mountainous wastelands for their phosphate solubilization and siderophore and IAA production to identify these fungal isolates by analyzing their morphological characteristics and molecular sequences (ITS, CAM, TUB, and RPB2) and to evaluate their eggplant growth-promoting ability in immature soil. This will allow the potential fungal isolates to develop effective PGP agents for use in the production of mountainous eggplant.

\section{Materials and Methods}

\subsection{Soil Sample Collection and Fungal Isolation}

In order to isolate PGP fungi, nine soil samples were collected in November 2019 from immature soil without plants in wastelands that had been abandoned for many years. The wastelands were located in a mountainous rural area of Yaolin town, Tonglu country $\left(119^{\circ} 20^{\prime} 56^{\prime \prime} \mathrm{E}, 29^{\circ} 50^{\prime} 7^{\prime \prime} \mathrm{N}\right)$, Zhejiang Province, China. The soils have a $\mathrm{pH}$ of 5.03 , with $0.072 \%$ of total N, $2.42 \mathrm{mg} / \mathrm{kg}$ of available $\mathrm{P}$, and $61.57 \mathrm{mg} / \mathrm{kg}$ of available $\mathrm{K}$, while the soil type is acrisols (acidic soils with a layer of clay accumulation), according to the soil classification system of FAO-UNESCO. The soils were sampled from a 5-20 cm soil layer. Each sample was placed into a sterilized polythene bag and then stored in a refrigerator at $4{ }^{\circ} \mathrm{C}$. Fungal isolation was carried out by preparing a series of 10 -fold dilutions of soil suspension from each sample and then inoculating $200 \mu \mathrm{L}$ aliquots on potato dextrose

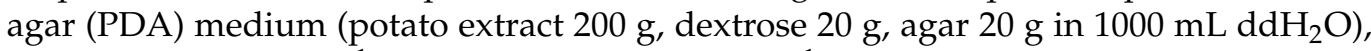
containing $100 \mu \mathrm{g} \cdot \mathrm{mL}^{-1}$ of ampicillin and $50 \mu \mathrm{g} \cdot \mathrm{mL}^{-1}$ of streptomycin sulphate. The plates were incubated at $25^{\circ} \mathrm{C}$ for $3-5$ days. The different colonies were chosen based on their morphological characteristics, and then each selected colony was purified via single-spore isolation. The purified isolates were stored in $1.5 \mathrm{~mL}$ tubes with $20 \%$ glycerol at $-70{ }^{\circ} \mathrm{C}$.

\subsection{Determination of Phosphate-Solubilizing Ability}

The 162 fungal isolates were inoculated on a modified NBRI-MTSB medium (glucose $10 \mathrm{~g}, \mathrm{MgCl}_{2} 5 \mathrm{~g}, \mathrm{KCl} 0.2 \mathrm{~g}, \mathrm{MgSO}_{4} \cdot 7 \mathrm{H}_{2} \mathrm{O} 0.25 \mathrm{~g},\left(\mathrm{NH}_{4}\right)_{2} \mathrm{SO}_{4} 0.1 \mathrm{~g}, \mathrm{Ca}_{3}\left(\mathrm{PO}_{4}\right)_{2} 5 \mathrm{~g}$, agar $15 \mathrm{~g}$ in $1000 \mathrm{~mL} \mathrm{ddH} \mathrm{H}_{2} \mathrm{O}$; medium was adjusted to 7.0). Following the incubation at $25^{\circ} \mathrm{C}$ for 3 days, the phosphate $(\mathrm{P})$ solubility was determined as described in [12,13], by measuring the size of the fungal phosphate-solubilizing zone. This experiment was repeated twice with six replicates of each isolate.

\subsection{Determination of Siderophore Production}

In order to evaluate the isolates' ability to produce siderophores, the 162 isolates were grown on chrome azurol sulphonate (CAS) agar plates [14], in which $10 \times$ MM9 salts were prepared according to the method described by [15] in iron-depleted chemically-defined minimal medium (MM9). The prepared CAS agar plates were inoculated with the fungal isolates and then incubated at $25^{\circ} \mathrm{C}$ for 3 days. The production of the siderophore by the fungal isolates was determined by measuring the visible orange halos around colonies on 
media. According to their abilities of phosphate solubilization and siderophore production, specific fungal isolates were selected for further evaluation.

\subsection{Indole Acetic Acid (IAA) Detection}

In order to determine the effect of the selected isolates in the conversion of tryptophan to IAA under different $\mathrm{pH}$ conditions, the fungal isolates were grown on PDA. After incubation at $25^{\circ} \mathrm{C}$ for 3 days, the pieces ( $5 \mathrm{~mm}$ in diameter) containing hyphae were cut from the colony margin of each isolate and placed in glass test tubes containing $10 \mathrm{~mL}$ of PDB with different concentrations of tryptophan $(0.1,0.5,1$, and $1.5 \%)$ and different $\mathrm{pH}$ values ( $\mathrm{pH}$ 5.0, 7.0, and 9.0). The tubes were incubated at $28^{\circ} \mathrm{C}$ in a rotary shaker at $150 \mathrm{rpm}$ for 7 days. After centrifugation at $8000 \mathrm{rpm}$ for $5 \mathrm{~min}, 1 \mathrm{~mL}$ of supernatant from each tube was mixed with $4 \mathrm{~mL}$ Salkowski's reagent $\left(0.5 \mathrm{~mol} / \mathrm{L} \mathrm{FeCl}_{3} 15 \mathrm{~mL}, \mathrm{H}_{2} \mathrm{SO}_{4} 300 \mathrm{~mL}\right.$, $\mathrm{ddH}_{2} \mathrm{O} 500 \mathrm{~mL}$ ) [16], and then the mixture was incubated in the dark at room temperature for $30 \mathrm{~min}$. IAA production was able to be determined by observing the development of pink color. Furthermore, IAA concentration was calculated using a standard curve, which was prepared by measuring the optical density of standard IAA $\left(0-100 \mu \mathrm{g} \mathrm{mL}^{-1}\right)$ at a wavelength of $530 \mathrm{~nm}$ with a UV-Vis spectrophotometer (Perkin Elmer Lambda 35, Waltham, MA, USA) [17]. The amount of the produced IAA was expressed in micrograms for IAA secreted per unit of optical density.

\subsection{Morphological Identification}

For morphological observation, the screened single-spore isolates were grown on Czapek yeast autolysate (CYA) agar, malt extract autolysate (MEA) agar, and creatine agar (CREA) [18]. In detail, the isolates were inoculated at three points on each plate of each medium and incubated at 25 and $37^{\circ} \mathrm{C}$ in the dark for 7 days. Following washing with $70 \%$ ethanol, excess conidia were used for morphological observation. The fungal asexual structures were observed and measured using a Zeiss Axiophot 2 microscopy with Axiocam CCD camera and AxioVision digital imaging software (AxioVision Software Release 3.1., v.3-2002; Carl Zeiss Vision Imaging Systems, Zeiss, Jena, Germany).

\subsection{Phylogenetic Analysis}

After obtaining the results of morphological identification, phylogenic analysis of Penicillium and Aspergillus spp. was carried out using the four-locus combined ITS region, TUB, RPB2, and CaM gene dataset (Supplementary Materials Table S1). For Penicillium spp., we selected the best TIM2 + I + G or TIM2 + I + G model for MP or BIfor ITS; TrNef + $\mathrm{I}+\mathrm{G}$ or TrNef + I + G for CMD; TIM1 + I + G or TIM2ef + I + G for RPB2; and TIM1 + I + G or $\operatorname{TrNef}+\mathrm{G}$ for TUB.

For phylogenetic analysis, genomic DNA of four isolates was extracted using a protocol, as described by [19]. The obtained genomic DNA was resuspended in $50 \mu \mathrm{L}$ TE buffer and stored at $-20^{\circ} \mathrm{C}$. Four loci sequences were amplified in an automated thermal cycler (Eppendorf AG, Germany). The primer pairs ITS5 and ITS4 were used for amplification of rDNA ITS regions [20], primers Bt2a ( $5^{\prime}$ - GGT AAC CAA ATC GGT GCT TTC $\left.-3^{\prime}\right)$ and Bt2b (5'- ACC CTC AGT GTA GTG ACC CTT GGC - $3^{\prime}$ ) for the beta-tubulin gene (TUB) [21], primers 5F (5'- GAY MGW GAT CAY TTY GG - $\left.3^{\prime}\right)$ and 7CR (5'- CCC ATR GCT TGY TTR CCC AT $-3^{\prime}$ ) for the RNA polymerase II subunit B (RPB2) gene [22], and primers CMD5 (5'CCG AGT ACA AGG ARG CCT TC - $3^{\prime}$ ) and CMD6 (5'- CCG ATR GAG GTC ATR ACG TGG - $3^{\prime}$ ) for the calmodulin gene [23]. The amplification was carried out in a $50 \mu \mathrm{L}$ reaction volume containing $32.5 \mu \mathrm{L}$ ddH $_{2} \mathrm{O}, 5 \mu \mathrm{L} 10 \times$ PCR buffer, $4 \mu \mathrm{L}$ of $2.5 \mathrm{mM}$ dNTP, $2 \mu \mathrm{L}$ of $10 \mu \mathrm{M}$ of each primer, $4 \mu \mathrm{L}$ template, and DNA $0.5 \mu \mathrm{L} 5 \mathrm{U} / \mu \mathrm{L}$ Taq DNA polymerase (TaKaRa Bio Inc., Shiga, Japan). The thermal cycling program was performed as described by [20]. Annealing temperatures for each PCR action were $52{ }^{\circ} \mathrm{C}$ for rDNA ITS regions, $55{ }^{\circ} \mathrm{C}$ for TUB, $50{ }^{\circ} \mathrm{C}$ for RPB2, and $55^{\circ} \mathrm{C}$ for the CMD gene. The purified PCR products were submitted to Sangon Biotech Co., Ltd. (Shanghai, China) for sequencing in both directions. 
The obtained sequences were assembled and edited using DNASTAR Lasergene v7.0.1 (DNAStar Inc., Madison, WI, USA) and BioEdit software 7.0.9 (North Carolina St. University, Raleigh, NC, USA) [24] and then analyzed by BLAST search in the GenBank sequence database. Based on the morphological identification, sequences of closely related species were downloaded (Table S1 in Supplementary Materials), and sequences of each loci were aligned with MAFFT 7.273 (http:/ / mafft.cbrc.jp/alignment/server/, accessed on 15 September 2021) [25] and trimmed with Gblocks 0.91b (http://molevol.cmima. csic.es/castresana/Gblocks_server.html, accessed on 15 September 2021) to eliminate the ambiguously aligned positions and divergent regions prior to phylogenetic analyses [26]. The model of evolution applied to each alignment was estimated by using jModel Test 2.1.7 (http:/ / evomics.org/resources/software/molecular-evolution-software/modeltest/, accessed on 15 September 2021) according to the Akaike information criterion [27], and phylogenic trees were constructed with RaxmlGUI v.2.0 (https: / / antonellilab.github.io/ raxmlGUI/ raxmlGUI, accessed on 15 September 2021) for the maximum likelihood (ML) method [28] and with MrBayes v. 3.2.6 (http://mrbayes.csit.fsu.edu, accessed on 15 September 2021) for Bayesian inference (BI).

\subsection{Effect of Isolates on Plant Growth Promotion in New Reclamation Land}

The PGP effects of the four selected isolates were evaluated by applying them to the seedlings of the eggplant cv. Hangqie 2010 (an eggplant F1 hybrid bred by the Vegetable Institution, Hangzhou Academy of Agricultural Sciences). In brief, the seeds were sterilized with $2 \%$ sodium hypochlorite solution for $2 \mathrm{~min}$, rinsed three times with sterile water, soaked in sterile water for $5 \mathrm{~h}$, and then air dried in a laminar flow hood. Subsequently, they were placed onto the surfaces of the wet sterilized filter papers and incubated at $25^{\circ} \mathrm{C}$ for 3 days. The germinated seeds were sown into the 32 cells of seed-growing trays containing cocopeat substrate (Bairun Agricultural Technology Co., Ltd., Hangzhou, China) and moved to a greenhouse with a relative humidity level of $70-80 \%$ and a temperature of $25^{\circ} \mathrm{C}$. Fungal conidia suspension for each isolate was prepared with sterile distilled water by suspending conidia harvested from 7-10-day-old cultures grown on PDA medium at $25^{\circ} \mathrm{C}$. The final concentration was determined using a hematocytometer. All the tested fungi had a concentration of $10^{6}$ spores $/ \mathrm{mL}$. When plants grew to the four-leaf stage, they were transplanted into pots containing unsterilized soil from the new reclamation land with $\mathrm{pH} 5.0$, and $10 \mathrm{~mL}$ of conidia suspension of each test isolate was poured into the soil around the plants and then incubated under the same conditions as described above. Eggplant inoculation with sterile water was used as the control. Thirty plants $(n=30)$ were used for each treatment, and three independent replicates were performed for each treatment. After growth for 30 days, eggplant seedlings were removed out from the pots and rinsed with tap water. The PGP ability of the fungal isolates was determined by measuring the seedlings' height, tap root length, and dry and fresh weights. Dry weights were measured by drying plant organs in an oven at $65^{\circ} \mathrm{C}$ for 2 days. The growth promotion efficacy $(\mathrm{GPE} \%)$ was assessed using the following formula: GPE $\%=($ treatment - control $) /$ control $\times 100 \%$.

\subsection{Statistical Analysis}

Statistical analyses were carried out using SPSS software version 16 (SPSS, Chicago, IL, USA). The levels of significance $(p<0.05)$ of the main treatments and their interactions were calculated through an analysis of variance after testing for normality and variance homogeneity.

\section{Results}

\subsection{Fungal Isolation and Screening of Phosphate-Solubilizing Ability}

The results of this study indicate that a total of 162 fungal isolates were obtained from nine soil samples. Furthermore, P solubilization assays showed that five isolates can produce a halo with a diameter $>3.40 \mathrm{~cm}$, indicating that these isolates have a great 
phosphate solubilization ability on the modified NBRI-MTSB media (Figure 1). In detail, the diameter of the halo was 4.20, 3.88, 3.62, 3.60, and $3.48 \mathrm{~cm}$ for isolates HZ123, HZ23, HZ22, HZ10, and HZ06, respectively. Furthermore, isolate HZ123 produced the largest zone, which was significantly $(p<0.05)$ higher than that of the other four isolates. In addition, there was no difference among the isolates HZ22, HZ10, and HZ06. This result suggested that the five isolates can be used to develop P solubilization agents.

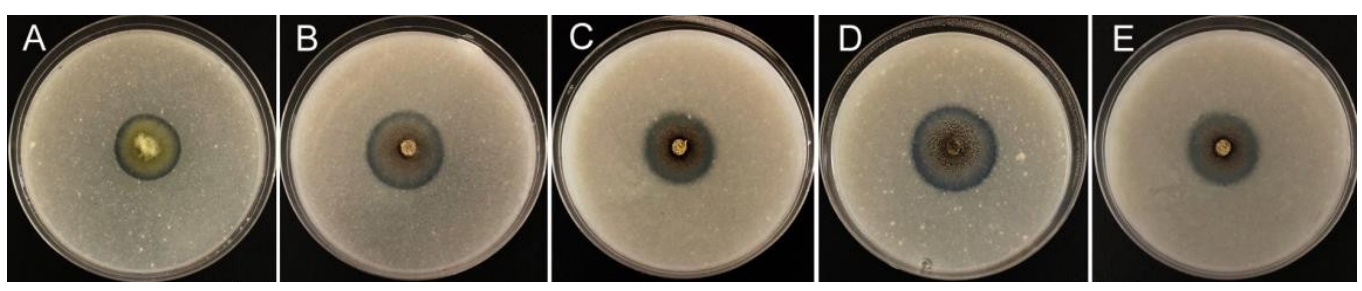

Figure 1. Phosphate solubilization assays of five isolates on the modified NBRI-MTSB media. (A) HZ06. (B) HZ23. (C) HZ10. (D) HZ123. (E) HZ22.

\subsection{Siderophore Production}

The results of this study indicate that around $82 \%$ of all isolates were able to produce visible orange halos with different sizes around fungal colonies on CAS media after 3 days of incubation, revealing the production of siderophore. Among the above-mentioned five P-solubilizing isolates, no halo was observed in isolate HZ22, but clear halos were found in the other four isolates. The diameters of the halos were 2.78, 2.05, 1.23 , and $1.04 \mathrm{~cm}$ for isolates HZ123, HZ06, HZ23, and HZ10, respectively. Furthermore, isolate HZ123 exhibited the largest halo diameter, which was significantly greater than that of the other three isolates (Figure 2). In addition, there was no significant difference in halo diameter between isolates HZ23 and HZ10. According to the abilities of phosphate solubilization and siderophore production, four isolates were selected for further analysis.

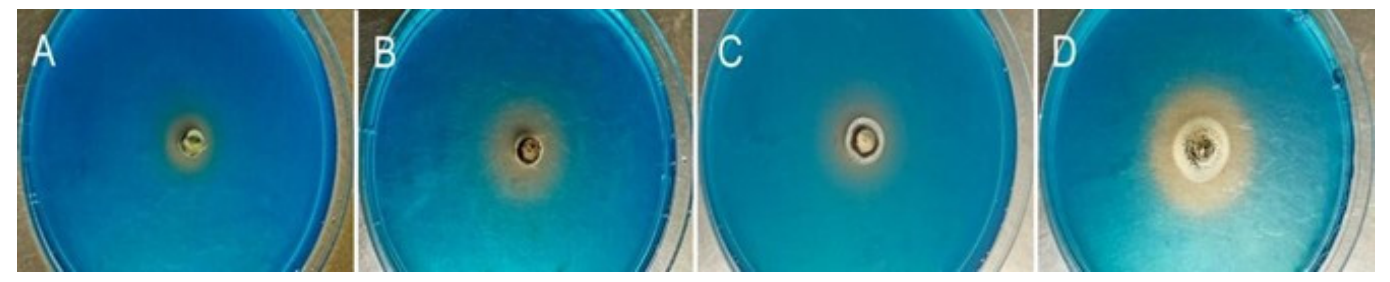

Figure 2. Siderophore production of four isolates on CAS media. (A) HZ06. (B) HZ23. (C) HZ10. (D) HZ123.

\subsection{Indole Acetic Acid (IAA) Detection}

The results of this study indicate that the four isolates differed in IAA production in the medium amended with different concentrations of tryptophan at different $\mathrm{pH}$ values. Indeed, isolate HZ123 exhibited the maximum production of IAA in the medium, amended with $1.5 \%$ tryptophan at $\mathrm{pH} 7.0$ with the concentration of $267.38 \mu \mathrm{g} / \mathrm{mL}$, while no significant $(p<0.05)$ difference was found in IAA production between $1.5 \%$ tryptophan at $\mathrm{pH} 7.0$ and $1.0 \%$ tryptophan at $\mathrm{pH} 5.0(238.75 \mu \mathrm{g} / \mathrm{mL})$ or $1.0 \%$ tryptophan at $\mathrm{pH} 7.0$ $(224.58 \mu \mathrm{g} / \mathrm{mL})$. Furthermore, isolate HZ10 exhibited strong production of IAA with the concentrations of 85.33 and $78.67 \mu \mathrm{g} / \mathrm{mL}$ in the medium with 1.5 and $1.0 \%$ tryptophan, respectively, at $\mathrm{pH}$ 9.0. In addition, isolates HZ06 and HZ23 exhibited weak production of IAA with the concentration of 73.92 and $71.50 \mu \mathrm{g} / \mathrm{mL}$, respectively, in the medium with $1.5 \%$ tryptophan at $\mathrm{pH} 9.0$ and $\mathrm{pH} 5.0$ (Figure 3 ). These results show that IAA production depended on the isolates, $\mathrm{pH}$, and concentrations of tryptophan in the medium. 

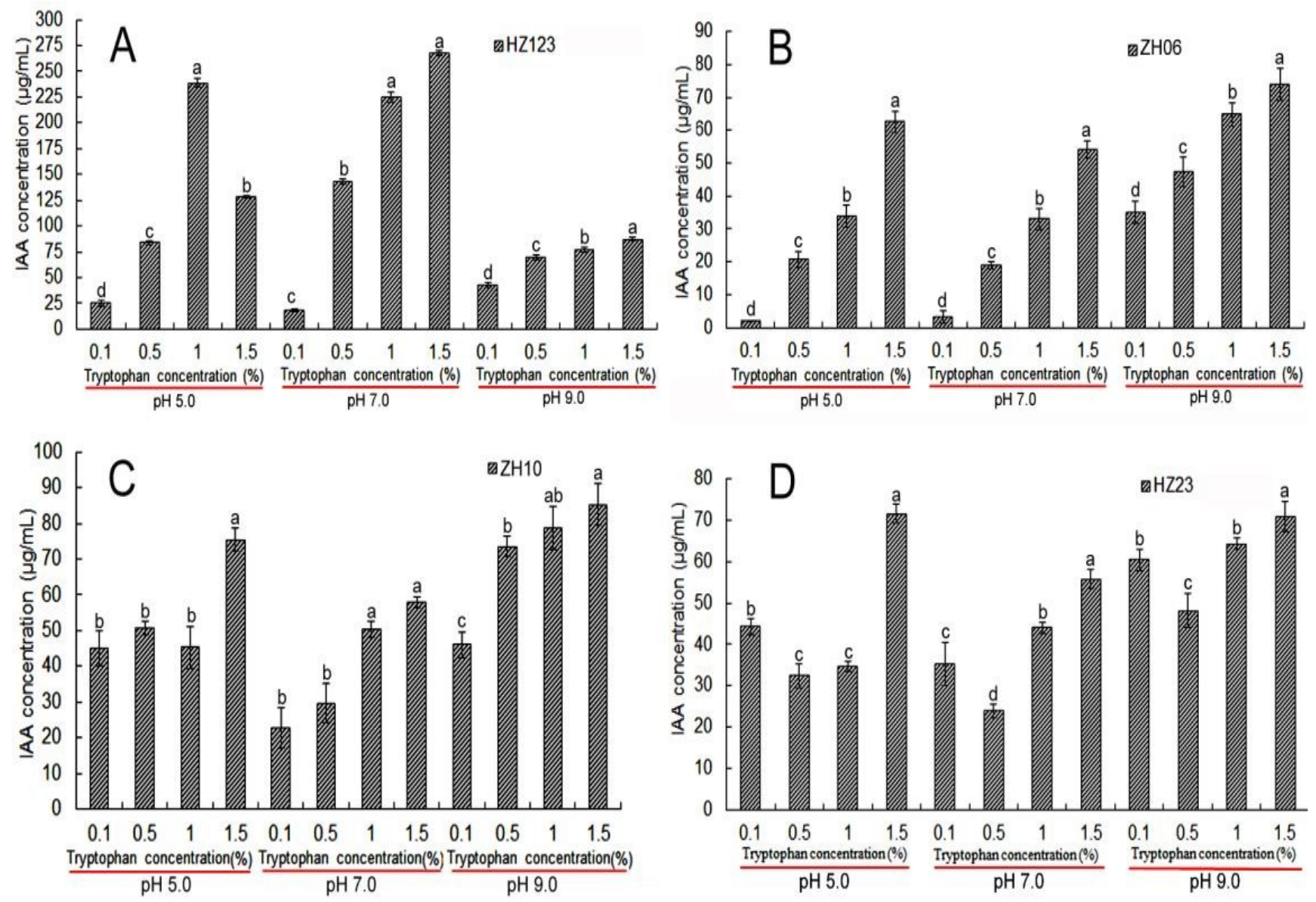

Figure 3. IAA production of the four isolates in the medium amended with different concentrations of tryptophan at different pH values. (A) HZ123. (B) HZ06. (C) HZ10. (D) HZ23. Values within the same treatment with different low-case letters are significantly different $(p \leq 0.05)$.

\subsection{Morphological Identification}

The results of this study indicate that the four isolates differed in colony diameter on CYA, MEA, CREA, and CYA medium and in organic acid production (Table 1). Based on the morphological characteristics of CYA, MEA, and CREA medium, the four fungal isolates were firstly divided into different genera. Indeed, isolate HZ06 was attributed to the genus Penicillium, in which colonies were in shades of green, mostly consisting of a dense felt of conidiophores, chains of single-celled conidia produced from the phialide. Furthermore, isolates HZ23, HZ10, and HZ123 were attributed to the genus Aspergillus Section Nigri due to the dark brown to black conidia, with uniseriate or biseriate conidiophores, spherical vesicles, and hyaline or lightly pigmented hyphae near the apex $[29,30]$.

Table 1. Colony diameter and organic acid production of four fungal isolates on different media.

\begin{tabular}{ccccccc}
\hline \multirow{2}{*}{ Isolates } & \multirow{2}{*}{ Identity } & \multicolumn{2}{c}{ Colony Diameter $(\mathbf{m m})$} & \multicolumn{2}{c}{ Acid } \\
\cline { 3 - 6 } & & CYA $\left(\mathbf{2 5}{ }^{\circ} \mathbf{C}\right)$ & MEA $\left(25^{\circ} \mathbf{C}\right)$ & CREA $\left(\mathbf{2 5}{ }^{\circ} \mathbf{C}\right)$ & CYA (37 $\left.{ }^{\circ} \mathbf{C}\right)$ & Production \\
\hline HZ06 & P. oxalicum & $18-21$ & $13-18$ & $12-15$ & $22-37$ & + \\
HZ123 & A. tubingensis & $52-60$ & $42-48$ & $10-14$ & $52-54$ & +++ \\
HZ10, 23 & A. brunneoviolaceus & $60-62$ & $46-50$ & $32-33$ & $22-29$ & ++ \\
\hline
\end{tabular}

CYA: CCYA: Czapek yeast autolysate; MEA: malt extract autolysate; CREA: creatine agar. Isolate HZ23 was identical to isolate HZ10. Acid production was determined by observing the color on CREA. +: weak; ++: strong; +++: very strong. 
In accordance with the description in [31], isolate HZ06 was identified as Penicillium oxalicum based on the colony growth patterns on different media under different temperatures after 7 days of incubation (Figure 4). In detail, on CYA at $25^{\circ} \mathrm{C}$, colonies: plane; margins: whitish; texture: velutinous to floccose; sporulation: dense; conidia: moderate yellowish green. On MEA at $25^{\circ} \mathrm{C}$, colonies: plane; marginal hyphae: submerged; texture: velutinous; conidia: yellowish green to dark yellowish green. On CREA at $25{ }^{\circ} \mathrm{C}$, acid production: poor, only in colony periphery; conidiophores: terminally branched, typically biverticillate with 1-3 metulae; stipes: smooth, most commonly 80-350 × 2.5-3.0 $\mu$; metulae of unequal length: 13.9-20.0 $\times$ 2.8-3.6 $\mu \mathrm{m}$; phialides: cylindrical with distinct collula of various sizes, 2-5 per metula, 10.7-13.0 $\times 2.0-3.0 \mu \mathrm{m}$; conidia: smooth, ellipsoidal, $4.2-5.3 \times 2.9-3.5 \mu \mathrm{m}, \mathrm{L} / \mathrm{W}$ ratio 1.4-1.5; sexual state not observed.
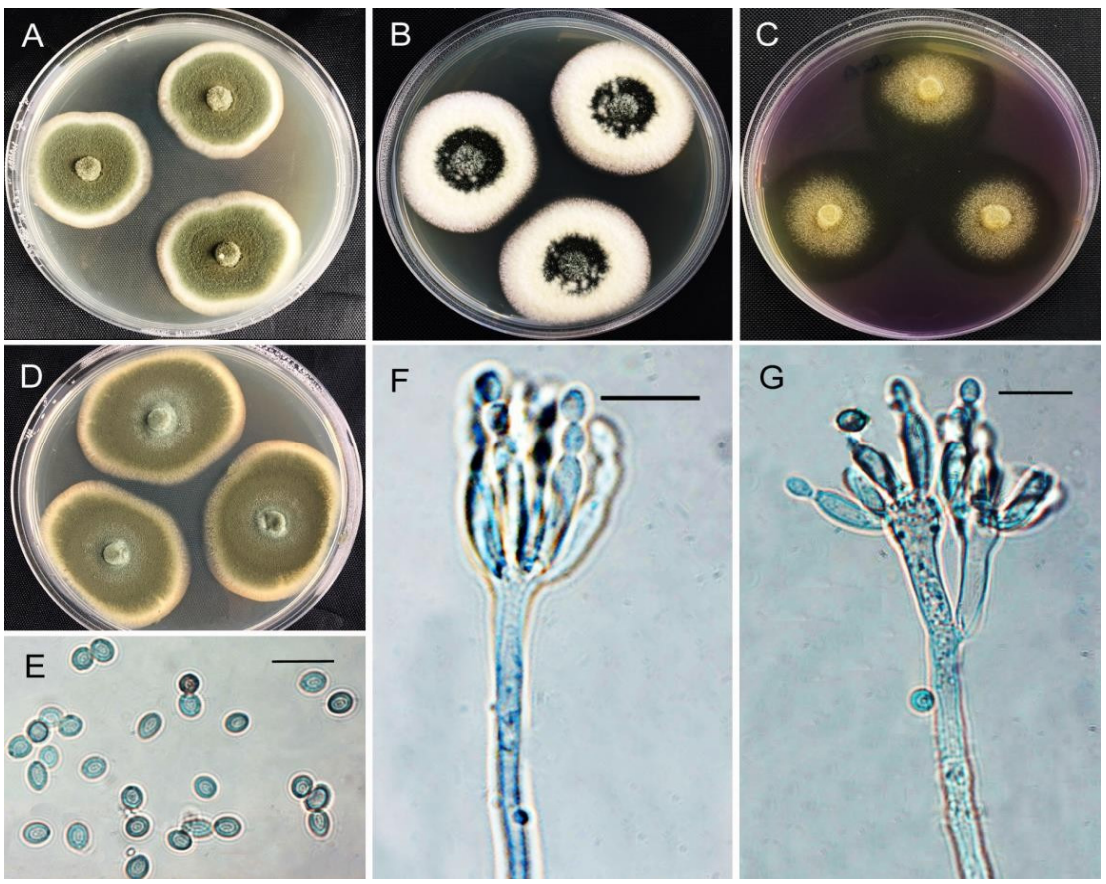

Figure 4. Penicillium oxalicum isolate HZ06. (A) Colonies on CYA after 7 days at $25^{\circ} \mathrm{C}$. (B) Colonies on MEA after 7 days at $25^{\circ} \mathrm{C}$. (C) Colonies on CREA after 7 days at $25^{\circ} \mathrm{C}$. (D) Colonies on CYA after 7 days at $37^{\circ} \mathrm{C}$. (E) Conidia. (F,G) Conidiophores. Scale bar $=10 \mu \mathrm{m}$.

In accordance with the description in [32], isolate HZ123 was identified as Aspergillus tubingensis based on the colony growth patterns on different media after 7 days of incubation (Figure 5). In detail, on CYA at $25^{\circ} \mathrm{C}$, colonies: generally, densely covered with conidial heads; conidial heads: brown to dark brown near black; commonly abundant, velutinous to slightly floccose, white to buff mycelium. Conidial heads: biseriate, radiate; stipes: 530-2200 $\mu \mathrm{m}$ long, 10-16 $\mu \mathrm{m}$ wide near vesicle, light brown, smooth; vesicles: globose to subglobose, (30-)31-57 $\mu \mathrm{m}$ in diameter; metulae: 3.6-5.6 × 2.5-4.6 $\mu \mathrm{m}$; phialides: 5.5-9.0 × 3.0-4.6 $\mu \mathrm{m}$ : conidia: globose to subglobose, 3.2-4.5 $\mu \mathrm{m}$, tuberculate to aculeate; sexual state not observed.

In accordance with the description in [33], isolates HZ23 and HZ10 with similar characteristics were identified as Aspergillus brunneoviolaceus based on the colony growth patterns on different media after 7 days of incubation (Figure 6). In detail, on CYA, conidial heads: brown to dark brown near black, velutinous to slightly floccose, white to buff mycelium. On MEA, conidial heads: brown; mycelium: white. On CREA, fungus displayed poor sporulation but commonly good to very good acid production at $25{ }^{\circ} \mathrm{C}$. Fungal stipes: smooth, hyaline, or slightly pigmented; vesicles: globose to ellipsoidal, 32-51 $\mu \mathrm{m}$ diam; conidial heads: uniseriate; phialides: $7-9 \times 3.5-4.5 \mu \mathrm{m}$, covering entire 
vesicle, conidia: globose to ellipsoidal, 3.5-4.5(-5) (avr. 4.0) × 3.1-4.0 (-4.1) (avr. 3.6) $\mu \mathrm{m}$, with coarsely roughened to echinulate surface.
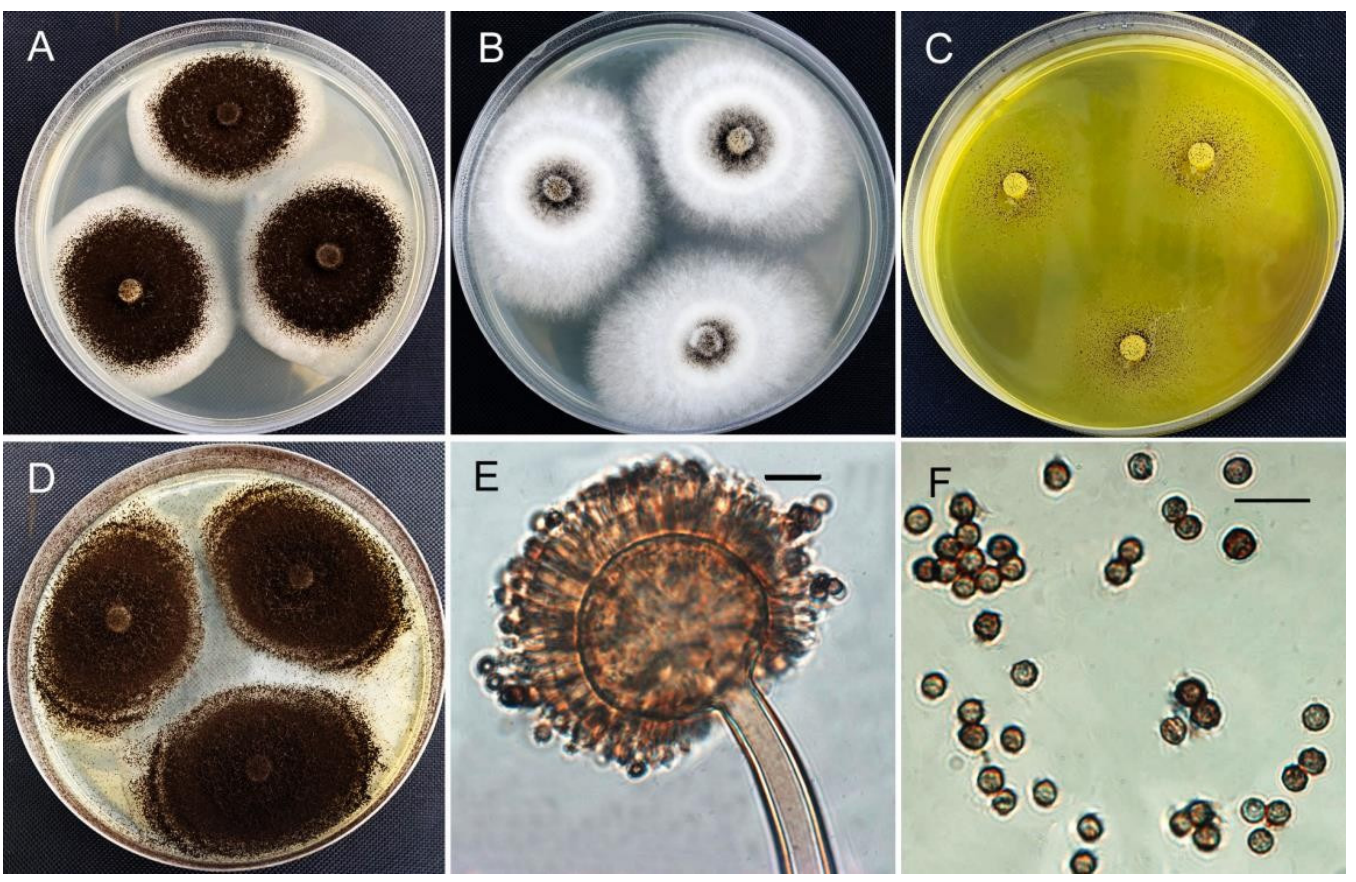

Figure 5. Aspergillus tubingensis isolate HZ123. (A) Colonies on CYA after 7 days at $25^{\circ} \mathrm{C}$. (B) Colonies on MEA after 7 days at $25^{\circ} \mathrm{C}$. (C) Colonies on CREA after 7 days at $25^{\circ} \mathrm{C}$. (D) Colonies on CYA after 7 days at $37^{\circ}$ C. (E) Conidiophores. (F) Conidia. Scale bars $=10 \mu \mathrm{m}$.
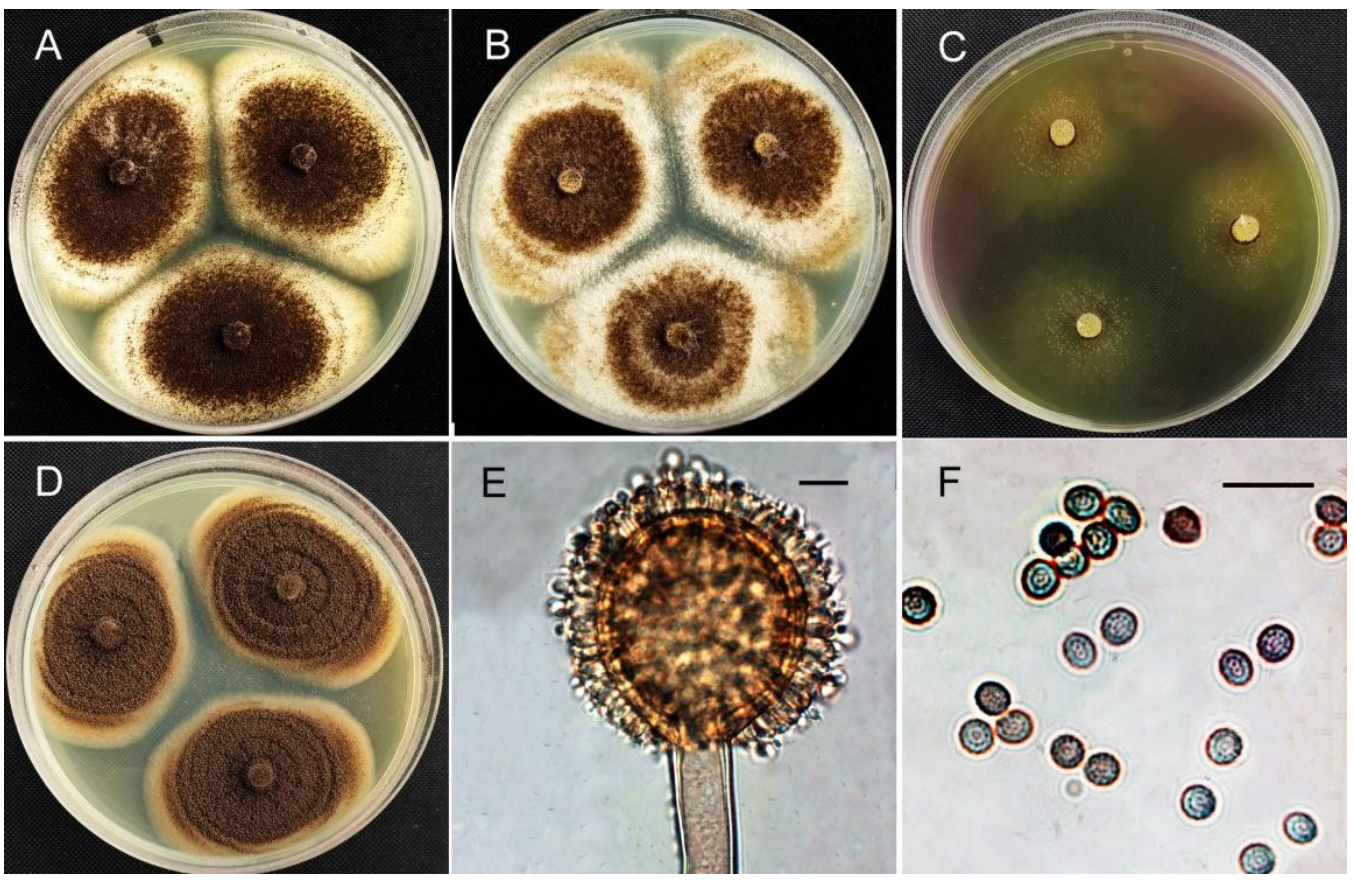

Figure 6. Aspergillus brunneoviolaceus HZ10. (A) Colonies on CYA after 7 days at $25^{\circ} \mathrm{C}$. (B) Colonies on MEA after 7 days at $25^{\circ} \mathrm{C}$. (C) Colonies on CREA after 7 days at $25^{\circ} \mathrm{C}$. (D) Colonies on CYA after 7 days at $37^{\circ} \mathrm{C}$. (E) Conidiophores. (F) Conidia. Scale bar $=10 \mu \mathrm{m}$. 


\subsection{Phylogenic Analysis of Sequence Data}

Molecular phylogenies were constructed with ITS, CaM, RPB2, and TUB data of 36 taxa, while Talaromyces flavus CBS310.38 ${ }^{\mathrm{T}}$ was used as an outgroup. The alignments were 1974 characters, of which 154 were phylogenetically informative after removing the ambiguously aligned regions. The phylogenetic analysis showed that the topology of the best scoring ML tree analysis was congruent with the BI tree for the concatenated fourlocus dataset (Figure 7). The relationship between all reference isolates could be clearly distinguished on the level of species. The tested isolate HZ06 clustered with the isolates of P. oxalicum $\left(5648\right.$, CV822, and CBS219.30 ${ }^{\mathrm{T}}$ ) as a distinct clade with high ML-BS $(84 \%)$ and BI-PP (1.00) support. For Aspergillus spp., the best TIM2 + I + G or TIM2ef + I +G model for MP or BI was selected for ITS, TIM3 $+\mathrm{I}+\mathrm{G}$ or TIM3 $+\mathrm{I}+\mathrm{G}$ for CMD, $\mathrm{TrN}+\mathrm{I}+\mathrm{G}$ or $\mathrm{TrNef}+\mathrm{I}+\mathrm{G}$ for RPB2, and TIM1+G or TIM1+G for TUB. A phylogenic tree was constructed with ITS, CMD, RPB2, and TUB data of 52 taxa, while A. robstus NRRL6362 ${ }^{\mathrm{T}}$ was used as an outgroup. The alignments were 2392 characters after removing the ambiguously aligned regions, of which 279 were phylogenetically informative. The phylogenetic analyses showed that the two tested isolates, HZ10 and HZ23, clustered with the isolates of A. brunneoviolaceus (PW4049, PW4122, and NRRL4912) as a distinct clade with high ML-BS (86\%) and BI-PP (1.00) support, while isolate HZ123 clustered with the isolates of $A$. tubingensis (NRRL62644, NRRL62643, NRRL62639, and NRRL4866) as a distinct clade with high ML-BS (100\%) and BI-PP (1.00) support (Figure 8).

In general, the results of this study indicate that morphological identification was identical to phylogenetic analysis. Therefore, it can be concluded that isolate HZO6 was identified as P. oxalicum, HZ123 was identified as A. tubingensis, and HZ23 and HZ10 were identified as A. brunneoviolaceus.

\subsection{Effect of Fungal Isolates on Plant Growth Promotion}

The results of PGP tests showed that the four isolates except HZ123 significantly promoted eggplant seedling growth at different levels under greenhouse conditions (Figure 9). Based on the phenotypic observation, inoculation of P. oxalicum HZ06 and A. brunneoviolaceus HZ23 and HZ10 caused an obvious increase in leaf size and root length compared to the control. Furthermore, the early flowering of eggplant was also affected by the isolates. Indeed, HZ06 blossomed abundantly after 27 days of colonization, while HZ10 occasionally blossomed after 29 days of colonization. However, HZ123 and HZ23 had not yet blossomed when harvested at 30 days (Figure 9).

The measured data showed that the four isolates significantly $(p<0.05)$ affected the growth and biomass accumulation of eggplants compared to the controls (Table 2). Inoculation with P. oxalicum HZ06 resulted in an increase of $22.35 \%, 39.26 \%$, and $47.69 \%$ in the length and dry and fresh weights of seedlings, respectively, and of $0.83 \%, 41.30 \%$, and $28.72 \%$ in the length and dry and fresh weights of roots compared to the control. Furthermore, inoculation with $A$. brunneoviolaceus HZ23 caused a $12.61 \%, 28.15 \%$, and $33.55 \%$ increase in the length and dry and fresh weights of seedlings, respectively, and a $1.99 \%, 28.26 \%$, and $27.70 \%$ increase in the length and dry and fresh weights of roots, respectively, compared to the control. In addition, inoculation with A. brunneoviolaceus HZ10 resulted in a $6.61 \%, 23.70 \%$, and $20.51 \%$ increase in the length and dry and fresh weights of seedlings, respectively, and a $8.12 \%, 43.48 \%$, and $35.81 \%$ increase in the length and dry and fresh weights of roots, respectively, compared to the control. In contrast, A. tubingensis HZ123 exhibited a negative effect on the seedlings' dry and fresh weights (Figure 9). 
Table 2. Effect of four fungus strains on growth promotion of eggplant 30 days after inoculation.

\begin{tabular}{|c|c|c|c|c|c|c|c|c|c|c|c|c|}
\hline Strains & SL (cm) & GPE (\%) & $\mathrm{RL}(\mathrm{cm})$ & GPE (\%) & SFW (g) & GPE (\%) & SDW (g) & GPE (\%) & RFW (g) & GPE $\%$ & RDW (g) & GPE $(\%)$ \\
\hline P. oxalicum $\mathrm{HZ} 06$ & $14.07 \pm 0.76$ & $22.35 \mathrm{a}$ & $27.83 \pm 0.98$ & $0.83 \mathrm{~b}$ & $9.29 \pm 0.96$ & $47.69 \mathrm{a}$ & $1.88 \pm 0.29$ & $39.26 \mathrm{a}$ & $3.81 \pm 0.46$ & $28.72 \mathrm{ab}$ & $0.65 \pm 0.08$ & $41.30 \mathrm{a}$ \\
\hline A. brunneoviolaceus HZ23 & $12.95 \pm 0.96$ & $12.61 \mathrm{~b}$ & $28.15 \pm 1.26$ & $1.99 \mathrm{~b}$ & $8.40 \pm 0.80$ & $33.55 \mathrm{~b}$ & $1.73 \pm 0.27$ & $28.15 \mathrm{~b}$ & $3.78 \pm 0.41$ & $27.70 \mathrm{~b}$ & $0.59 \pm 0.07$ & $28.26 \mathrm{~b}$ \\
\hline A. brunneoviolaceus HZ10 & $12.26 \pm 0.89$ & $6.61 \mathrm{c}$ & $29.84 \pm 1.54$ & $8.12 \mathrm{a}$ & $7.58 \pm 0.62$ & $20.51 \mathrm{c}$ & $1.67 \pm 0.26$ & $23.70 \mathrm{~b}$ & $4.02 \pm 0.68$ & $35.81 \mathrm{a}$ & $0.66 \pm 0.10$ & $43.48 \mathrm{a}$ \\
\hline A. tubingensis HZ123 & $12.50 \pm 0.89$ & $8.70 \mathrm{bc}$ & $30.10 \pm 2.58$ & $9.06 \mathrm{a}$ & $6.24 \pm 1.74$ & $-0.79 \mathrm{~d}$ & $1.32 \pm 0.14$ & $-2.22 c$ & $3.79 \pm 0.40$ & $28.04 \mathrm{~b}$ & $0.51 \pm 0.08$ & $10.87 \mathrm{c}$ \\
\hline Control & $11.50 \pm 0.53$ & - & $27.59 \pm 1.89$ & - & $6.29 \pm 0.84$ & - & $1.35 \pm 0.26$ & - & $2.96 \pm 0.37$ & - & $0.46 \pm 0.08$ & - \\
\hline
\end{tabular}

Means are averages \pm standard deviations (SD). Values in a column with different letters are significantly different by Student's $t$-test at $(p \leq 0.05)$. SL: seedling length; GPE: growth promotion efficacy; RL: root length; SFW: seedling fresh weight; SDW: seedling dry weight; RFW: root fresh weight; RDW: root dry weight.

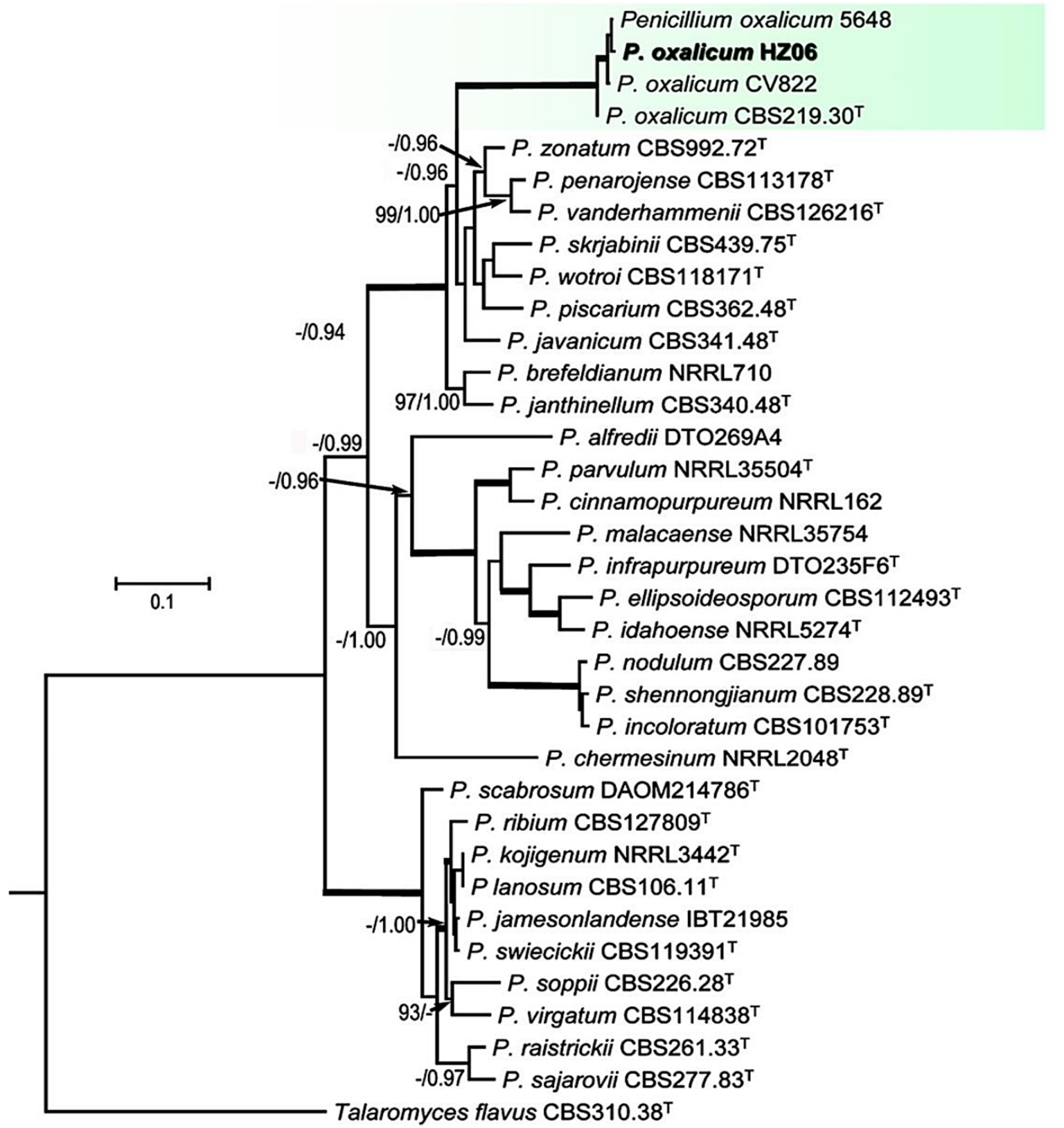

Figure 7. Maximum likelihood (ML) tree generated from the combined ITS region and TUB, RPB2, and CaM sequences of 36 taxa of Penicillium. The tree is rooted with Talaromyces flavus CBS310.38 ${ }^{\mathrm{T}}$. Clades with 100\% ML bootstrap branch support and 1.00 Bayesian posterior probabilities (BPP) are indicated by thick black lines. Clades with $>80 \%$ ML-BS (left) and 0.95 BPP (right) are indicated by the corresponding support values. Dashes indicate support values lower than $80 \%$ ML-BS and 0.95 BPP. Species isolated from soil are shown in bold. T: type strain. 


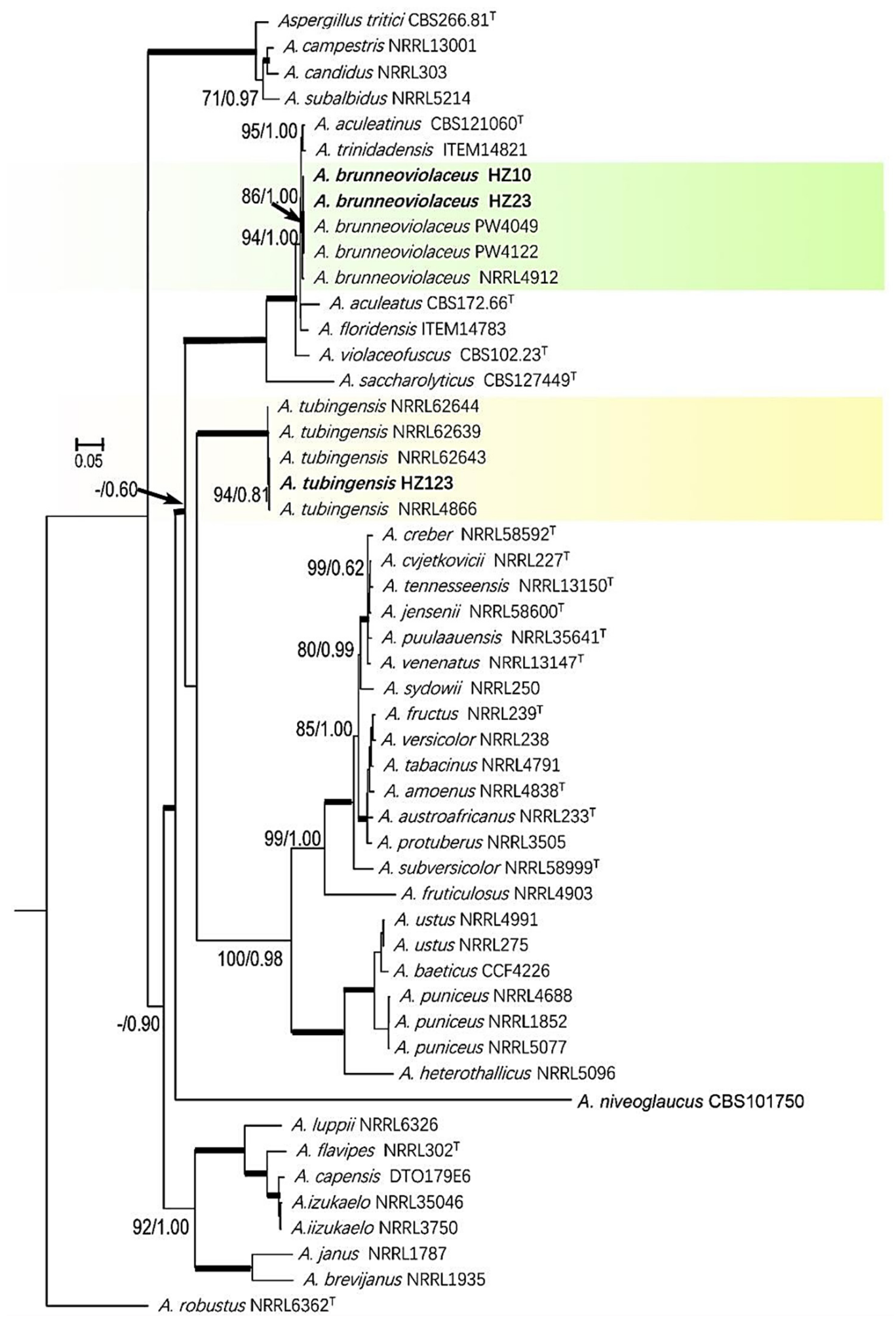

Figure 8. Maximum likelihood (ML) tree generated from the combined ITS region and TUB, RPB2, and CaM sequences of 52 taxa of Aspergillus. The tree is rooted with A. robstus NRRL6362 ${ }^{\mathrm{T}}$. Clades with $100 \%$ ML bootstrap support and 1.00 Bayesian posterior probabilities (BPP) are indicated by thick black lines. Clades with $>80 \%$ ML-BS (left) and 0.95 BPP (right) are indicated by the corresponding support values. Dashes indicate support values lower than 80\% ML-BS and 0.95 BPP. Species isolated from soil are shown in bold. T: type strain. 

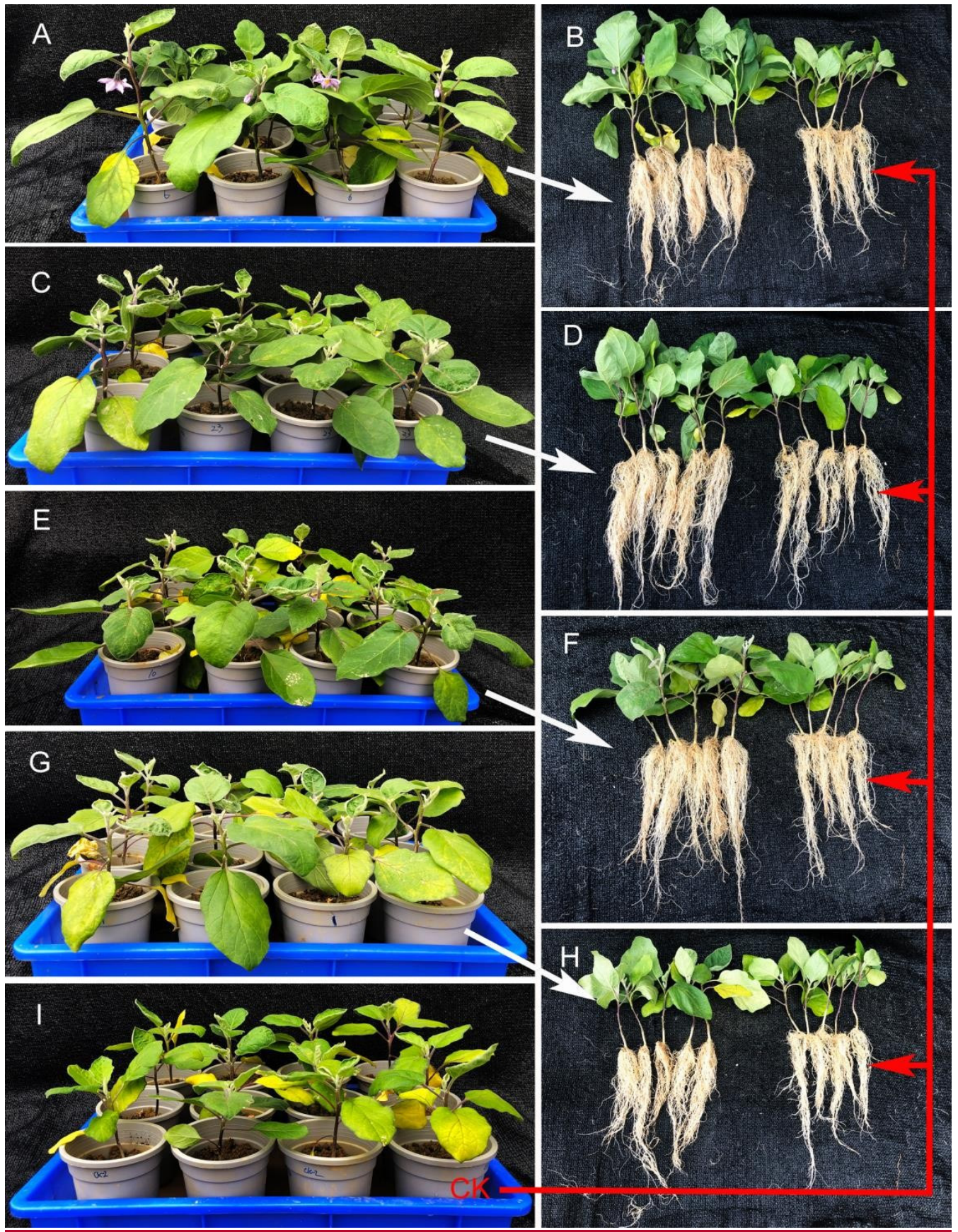

Figure 9. Effect of inoculation with four fungal isolates on eggplant growth in soil from new reclamation land 30 days after inoculation. Each treatment had three replicates with 30 plants in each replicate. The photos of plants were taken by randomly placing 12 plants from each treatment into one tray, while the photos of roots were taken by randomly picking up 5 plants from each treatment and then removing the soil from the roots. All control plants come from the uninoculated control treatment. (A) Inoculation with isolate HZ06; (B) roots from A; (C) inoculation with isolate HZ23; (D) roots from $\mathrm{C}$; $(\mathbf{E})$ inoculation with isolate HZ10; $(\mathbf{F})$ roots from E; $(\mathbf{G})$ inoculation with isolate HZ123; (H) roots from $\mathrm{G}$; (I) the uninoculated control.

\section{Discussion}

Immature soil is not suitable for plant growth, but it can be modified by adding organic matter and PGP microbes to promote soil maturity and plant growth [1-3]. However, little attention has been paid to the effect of PGP microbes on plant growth promotion in immature soil. In this study, the 162 fungal isolates were successfully isolated from 
the waste lands with poor nutrition. Among them, only four isolates, designated as HZ06, HZ23, HZ10, and HZ123, exhibited the ability to solubilize phosphate and produce siderophores and IAA. Furthermore, the four isolates HZ06, HZ23, HZ10, and HZ123 were identified as P. oxalicum, A. brunneoviolaceus, A. brunneoviolaceus, and A. tubingensis, respectively, based on both morphological observation and phylogenic analysis of sequence data.

As is well known, the effect of PGP microbes on various aspects of plant growth is often variable, depending largely on their successful survival, colonization, growth, and efficient adaptation to rapidly changing conditions. Interestingly, our previous study clearly showed that the growth of each strain in its original niche environment is significantly greater $(p<0.01$, Analysis of Variance (ANOVA) test) than that of the other strains under the same conditions, revealing the preference of each strain for a specific niche environment [34]. Therefore, it can be inferred that the four fungal isolates originating from wastelands may have greater potential to colonize in immature soil.

A considerable number of previous studies have been carried out with the aim of isolating and characterizing PGP fungi, including those belonging to the genera of Aspergillus and Penicillium [6,35-38]. For example, Araujo et al. [35] showed that Aspergillus niger can promote the growth of coffee seedlings in a substrate with no P limitation. Javed et al. [36] reported the potential of endophytic fungus Aspergillus terreus as a potent plant growth promoter. Furthermore, Wakelin et al. [37] reported the effect of Penicillium fungi on plant growth and phosphorus mobilization in neutral-to-alkaline soils from southern Australia. Gomez-Munoz et al. [38] found that Penicillium bilaii inoculation resulted in increased root growth and, thus, nutrient uptake and plant growth of maize. In contrast with these findings, this study reported the plant growth-promoting effect of Aspergillus and Penicillium in new reclamation soil.

According to the results of previous publications, the plant growth promotion mechanism of PGP fungi, in particular, Aspergillus spp. and Penicillium spp., can be, at least partially, attributed to the fact that they have the capacity to enhance the solubilization of insoluble phosphate compounds [39,40] and produce IAA [41,42] and siderophore [43,44]. In agreement with these results, the four fungal isolates that were screened in this study all possessed the above-mentioned properties of PGP fungi. In contrast with previous reports, the results of this study also found that these isolates were able to produce organic acids on CREA medium. Many studies have indicated that the organic acids that are secreted by PGP fungi may affect plant growth [45,46]; therefore, further studies should be carried out to explore the role of the organic acids in plant promotion of Aspergillus spp. and Penicillium spp. in new reclamation soil.

Phosphorus is one of the most indispensable macronutrients for the growth and development of plants. It is well known that the microbial solubilization of inorganic phosphates has been attributed mainly in regard to the production of organic acids. For example, Vyas and Gulati [45] reported that 19 phosphate-solubilizing fluorescent Pseudomonas strains produced gluconic acid, oxalic acid, 2-ketogluconic acid, lactic acid, succinic acid, formic acid, citric acid, and malic acid in culture filtrates during the solubilization of inorganic phosphate. In agreement with this result, the four fungal isolates examined in the current study were able to solubilize $\mathrm{P}$ and produce organic acids. Interestingly, A. tubingensis HZ123 exhibited the best abilities of both $P$ solubilization and organic acids production, while there was poor organic acid production in P. oxalicum HZ06, which had a weak ability of $\mathrm{P}$ solubilization. This indicates the correlation between P solubilization and organic acid production.

Furthermore, previous studies have also shown that the species P. oxalicum is tolerant to low and high $\mathrm{pH}$ for its survival [47], while soil amendment with $A$. tubingensis has been found to be able to enhance corn yield through its ability to dissolve phosphates into soil and reduce alkalinity in bauxite residues [48]. In contrast, in vivo PGP tests in this study indicated that the P. oxalicum HZ06 was a better PGP fungus than HZ123, although A. tubingensis HZ123 showed the best abilities of P solubilization and siderophore and 
IAA production among the four isolates in the in vitro experiments, while P. oxalicum HZ06 exhibited the worst abilities of $\mathrm{P}$ solubilization and siderophore and IAA production. Differences in results between in vitro and in vivo tests may be due to the biological nature of different fungal species.

In agreement with the result of this study, P. oxalicum has been reported to be able to utilize phosphate and contribute to soil fertilization $[6,49]$; several strains are patented as biofertilizers, commercial enzyme producers, or degraders of waste plant biomass and pollutants [31]. Furthermore, some studies indicate that P. oxalicum is a producer of natural products, including organic acids (oxalic, formic, tartaric, malic, acetic, and citric acids), various enzymes, mycotoxins, cytotoxic alkaloids, and even cytotoxic compounds [6,31], which may be a possible cause of the promoting effect of isolate HZO6 on the early flowering of the plant. On the other hand, our recent studies have indicated that different organic fertilizers can improve soil from newly reclaimed land to crop soil. Therefore, further studies should be carried to elucidate the plant growth-promoting mechanism of these fungal isolates, in particular HZ06, alone or in combination with organic amendments in new reclamation land.

\section{Conclusions}

In summary, our results successfully isolated and characterized the four PGP fungal isolates from wastelands via P solubilization and IAA and siderophore production. Based on the results of the morphological and molecular analyses, isolate HZ06 was identified as $P$. oxalicum, isolates HZ23 and HZ10 were identified as A. brunneoviolaceus, and isolate HZ123 was identified as $A$. tubingensis. The results of the in vivo plant growth test demonstrated that the fungal isolates, in particular isolate HZ06, have great potential as plant growthpromoting fungi to develop biofertilizer for application in eggplant production in immature soil from new reclamation land.

Supplementary Materials: The following are available online at https:/ /www.mdpi.com/article/10 .3390 /agriculture11111036/s1, Table S1: Strains and sequence accession numbers in this study.

Author Contributions: Conceptualization, X.L., D.L., J.Y., Y.Z., H.W., J.Z., T.A. and B.L.; methodology, X.L., D.L. and T.A.; software, X.L. and D.L.; validation, X.L. and D.L.; formal analysis, X.L., D.L., Y.Z., H.W. and T.A.; investigation, X.L. and D.L.; resources, X.L., D.L., J.Y. and J.Z.; data curation, X.L. and J.Y.; writing—original draft preparation, X.L., D.L., J.Y., Y.Z., H.W., J.Z., T.A. and B.L.; writing—review and editing, J.Y., J.Z. and B.L.; visualization, J.Y., J.Z. and B.L.; supervision, J.Y., J.Z. and B.L.; project administration, J.Y. and J.Z.; funding acquisition, J.Y. and J.Z. All authors have read and agreed to the published version of the manuscript.

Funding: This research was funded by the key research and development program of Zhejiang province (2019C02035) and the Science and Technology Innovation and Promotion Demonstration project of Hangzhou Academy of Agricultural Sciences (2020HNCT-12, 2019HNCT-03).

Institutional Review Board Statement: Not applicable.

Informed Consent Statement: Not applicable.

Data Availability Statement: The nucleotide sequences generated in this study were deposited at: https:/ / www.ncbi.nlm.nih.gov/genbank20210517 (accessed on 17 May 2021).

Conflicts of Interest: The authors declare no conflict of interest.

\section{References}

1. Li, X.Q.; Su, Y.; Ahmed, T.; Ren, H.Y.; Javed, M.R.; Yao, Y.L.; An, Q.L.; Yan, J.L.; Li, B. Effects of different organic fertilizers on improving soil from newly reclaimed land to crop soil. Agriculture 2021, 11, 560. [CrossRef]

2. Larney, F.J.; Angers, D.A. The role of organic amendments in soil reclamation: A review. Can. J. Soil Sci. 2012, 92, 19-38. [CrossRef]

3. Rashid, M.I.; Mujawar, L.H.; Shahzad, T.; Almeelbi, T.; Oves, M. Bacteria and fungi can contribute to nutrients bioavailability and aggregate formation in degraded soils. Microbiol. Res. 2016, 183, 26-41. [CrossRef]

4. Souza, R.D.; Ambrosini, A.; Passaglia, L.M.P. Plant growth-promoting bacteria as inoculants in agricultural soils. Genet. Mol. Biol. 2015, 38, 401-419. [CrossRef] 
5. Zhang, F.; Huo, Y.; Cobb, A.B.; Luo, G.; Zhou, J.; Yang, G.; Wilson, G.W.T.; Zhang, Y. Trichoderma biofertilizer links to altered soil chemistry, altered microbial communities, and improved grassland biomass. Front. Microbiol. 2018, 9, 848. [CrossRef]

6. Li, Z.; Bai, T.; Dai, L.; Wang, F.; Tao, J.; Meng, S.; Hu, Y.; Wang, S.; Hu, S. A study of organic acid production in contrasts between two phosphate solubilizing fungi: Penicillium oxalicum and Aspergillus niger. Sci. Rep. 2016, 6, 25313. [CrossRef] [PubMed]

7. Narsian, V.; Patel, H.H. Aspergillus aculeatus as a rock phosphate solubilizer. Soil Biol. Biochem. 2000, 32, 559-565. [CrossRef]

8. Haas, H. Fungal siderophore metabolism with a focus on Aspergillus fumigates. Nat. Prod. Rep. 2014, 31, 1266-1276. [CrossRef] [PubMed]

9. Kumar, N.V.; Rajam, K.S.; Rani, M.E. Plant growth promotion efficacy of indole acetic acid (iaa) produced by a mangrove associated fungi-Trichoderma viride vkf3. Int. J. Curr. Microbiol. 2017, 6, 2692-2701. [CrossRef]

10. Lee, S.; Yap, M.; Behringer, G.; Hung, R.; Bennett, J.W. Volatile organic compounds emitted by Trichoderma species mediate plant growth. Fungal Biol. Biotechnol. 2016, 3, 7. [CrossRef] [PubMed]

11. Hossain, M.M.; Sultana, F. Application and mechanisms of plant growth promoting fungi (PGPF) for phytostimulation. In Organic Agriculture; IntechOpen: London, UK, 2020; pp. 1-31.

12. Mehta, S.; Nautiyal, C.S. An efficient method for qualitative screening of phosphate solubilizing bacteria. Curr. Microbiol. 2001, 43, 51-55. [CrossRef]

13. Tang, A.; Haruna, A.O.; Majid, N.M.A.; Jalloh, M.B. Potential PGPR properties of cellulolytic, nitrogen-fixing, phosphatesolubilizing bacteria in rehabilitated tropical forest soil. Microorganisms 2020, 8, 442. [CrossRef]

14. Wang, X.X.; Zhang, M.C.; Loh, B.; Leptihn, S.; Ahmed, T.; Li, B. A novel NRPS cluster, acquired by horizontal gene transfer from algae, regulates siderophore iron metabolism in Burkholderia seminalis R456. Int. J. Biol. Macromol. 2021, 182, 838-848. [CrossRef] [PubMed]

15. Murugappan, R.M.; Aravinth, A.; Karthikeyan, M. Chemical and structural characterization of hydroxamate siderophore produced by marine Vibrio harveyi. J. Ind. Microbiol. Biotechnol. 2011, 38, 265-273. [CrossRef]

16. Khamna, S.; Yokota, A.; Lumyong, S. Actinomycetes isolated from medicinal plant rhizosphere soils: Diversity and screening of antifungal compounds, indole-3-acetic acid and siderophore production. World J. Microbiol. Biotechnol. 2009, 25, 649-655. [CrossRef]

17. Raut, V.; Shaikh, I.; Naphade, B.; Prashar, K.; Adhapure, N. Plant growth promotion using microbial IAA producers in conjunction with azolla: A novel approach. Chem. Biol. Technol. 2017, 4, 1. [CrossRef]

18. Samson, R.A.; Visagie, C.M.; Houbraken, J.; Hong, S.B.; Hubka, V.; Klaassen, C.H.W.; Perrone, G.; Seifert, K.A.; Susca, A.; Tanney, J.B.; et al. Phylogeny, identification and nomenclature of the genus Aspergillus. Stud. Mycol. 2014, 78, 141-173. [CrossRef]

19. Zhang, J.Z.; Li, M.J. A new species of Bipolaris from the halophyte Sesuvium portulacastrum in Guangdong Province, China. Mycotaxon 2009, 109, 289-300. [CrossRef]

20. Tomaha, A.A.; Abd Alamera, I.S.; Li, B.; Zhang, J. A new species of Trichoderma and gliotoxin role: A new observation in enhancing biocontrol potential of T. virens against Phytophthora capsici on chili pepper. Biol. Control. 2020, 145, 104261. [CrossRef]

21. Nasri, T.; Hedayati, M.T.; Abastabar, M.; Pasqualotto, A.C.; Armaki, M.T.; Hoseinnejad, A.; Nabili, M. PCR-RFLP on beta-tubulin gene for rapid identification of the most clinically important species of Aspergillus. J. Microbiol. Methods 2015, 117, 144-147. [CrossRef] [PubMed]

22. Haituk, S.; Suwannarach, N.; Hongsanan, S.; Senwanna, C.; Cheewangkoon, R. New genus of epiphytic sooty mold: Alloscorias syngonii (Readerielliopsidaceae) from Thailand. Phytotaxa 2021, 507, 271-282. [CrossRef]

23. Hong, S.B.; Go, S.J.; Shin, H.D.; Frisvad, J.C.; Samson, R.A. Polyphasic taxonomy of Aspergillusfumigatus and related species. Mycologia 2005, 97, 1316-1329. [CrossRef]

24. Tippmann, H.F. Analysis for free: Comparing programs for sequence analysis. Brief. Bioinform. 2004, 5, 82-87. [CrossRef] [PubMed]

25. Katoh, K.; Standley, D.M. MAFFT multiple sequence alignment software version 7: Improvements in performance and usability. Mol. Biol. Evol. 2013, 30, 772-780. [CrossRef] [PubMed]

26. Katoh, K.; Munkhbata, B.; Tounaia, K.; Manoa, S.; Andoa, H.; Oyungerelb, G.; Chaec, G.T.; Hand, H.; Jiae, G.J.; Tokunagaf, K.; et al Genetic features of Mongolian ethnic groups revealed by Y-chromosomal analysis. Gene 2005, 346, 63-70. [CrossRef] [PubMed]

27. Darriba, D.; Taboada, G.L.; Doallo, R.; Posada, D. jModelTest 2: More models, new heuristics and parallel computing. Nat. Methods 2012, 9, 772. [CrossRef]

28. Silvestro, D.; Michalak, I. raxmlGUI: A graphical front-end for RAxML. Org. Divers. Evol. 2012, 12, 335-337. [CrossRef]

29. Tsang, C.C.; Tang, J.Y.M.; Lau, S.K.P.; Woo, P.C.Y. Taxonomy and evolution of Aspergillus, Penicillium and Talaromyces in the omics era-Past, present and future. Comput. Struct. Biotechnol. 2018, 16, 197-210. [CrossRef]

30. Houbraken, J.; Kocsube, S.; Visagie, C.M.; Yilmaz, N.; Wang, X.C.; Meijer, M.; Kraak, B.; Hubka, V.; Bensch, K.; Samson, R.A.; et al. Classification of Aspergillus, Penicillium, Talaromyces and related genera (Eurotiales): An overview of families, genera, subgenera, sections, series and species. Stud. Mycol. 2020, 95, 5-169. [CrossRef]

31. Kubátová, A.; Hujslová, M.; Frisvad, J.C.; Chudíčková, M.; Kolařík, M. Taxonomic revision of the biotechnologically important species Penicillium oxalicum with the description of two new species from acidic and saline soils. Mycol. Prog. 2019, 18, 215-228. [CrossRef]

32. Horn, B.W.; Olarte, R.A.; Peterson, S.W.; Carbone, I. Sexual reproduction in Aspergillus tubingensis from section Nigri. Mycologia 2013, 105, 1153-1163. [CrossRef] [PubMed] 
33. Jurjević, Z.; Peterson, S.W.; Stea, G.; Solfrizzo, M.; Varga, J.; Hubka, V.; Perrone, G. Two novel species of aspergillus section nigri from indoor air. IMA Fungus 2012, 3, 159-173. [CrossRef] [PubMed]

34. Zhu, B.; Ibrahim, M.; Cui, Z.Q.; Xie, G.L.; Jin, G.L.; Kube, M.; Li, B.; Zhou, X.P. Multi-omics analysis of niche specificity provides new insights into ecological adaptation in bacteria. ISME J. 2016, 10, 2072-2075. [CrossRef]

35. Araujo, V.C.; Rossati, K.F.; Xavier, L.V.; de Oliveira, V.A.; Carmo, G.J.D.; de Assis, G.A.; Mendes, G.D. Enhanced growth in nursery of coffee seedlings inoculated with the rhizosphere fungus Aspergillus niger for field transplantation. Rhizosphere 2020, 15, 100236. [CrossRef]

36. Javed, A.; Shah, A.H.; Hussain, A.; Shinwari, Z.K.; Khan, S.A.; Khan, W.; Jan, S.A. Potential of endophytic fungus Aspergillus terreus as potent plant growth promoter. Pak. J. Bot. 2020, 52, 1083-1086. [CrossRef]

37. Wakelin, S.A.; Gupta, V.V.S.R.; Harvey, P.R.; Ryder, M.H. The effect of Penicillium fungi on plant growth and phosphorus mobilization in neutral to alkaline soils from southern Australia. Can. J Microbiol. 2007, 53, 106-115. [CrossRef]

38. Gomez-Munoz, B.; Jensen, L.S.; de Neergaard, A.; Richardson, A.E.; Magid, J. Effects of Penicillium bilaii on maize growth are mediated by available phosphorus. Plant Soil 2018, 431, 159-173. [CrossRef]

39. Mendes, G.D.O.; Freitas, A.L.M.; Pereira, O.L.; Silva, I.R.; Vassilev, N.B.; Costa, M.D. Mechanisms of phosphate solubilization by fungal isolates when exposed to different P sources. Ann. Microbiol. 2014, 64, 239-249. [CrossRef]

40. Sharma, S.B.; Sayyed, R.Z.; Trivedi, M.H.; Gobi, T.A. Phosphate solubilizing microbes: Sustainable approach for managing phosphorus deficiency in agricultural soils. SpringerPlus 2013, 2, 587. [CrossRef]

41. Ikram, M.; Ali, N.; Jan, G.; Jan, F.G.; Rahman, I.U.; Iqbal, A.; Hamayun, M. IAA producing fungal endophyte Penicillium roqueforti Thom., enhances stress tolerance and nutrients uptake in wheatplants grown on heavy metal contaminated soils. PLoS ONE. 2018, 13, e0208150. [CrossRef]

42. Mehmood, A.; Hussain, A.; Irshad, M.; Hamayun, M.; Khan, N. In vitro production of IAA by endophytic fungus Aspergillus awamori and its growth promoting activities in zea mays. Symbiosis 2019, 77, 225-235. [CrossRef]

43. Chowdappa, S.; Jagannath, S.; Konappa, N.; Udayashankar, A.C.; Jogaiah, S. Detection and characterization of antibacterial siderophores secreted by endophytic fungi from Cymbidium aloifolium. Biomolecules 2020, 10, 1412. [CrossRef]

44. Osman, Y.; Gebreil, A.; Mowafy, A.M.; Anan, T.I.; Hamed, S.M. Characterization of Aspergillus niger siderophore that mediates bioleaching of rare earth elements from phosphorites. World J. Microbiol. Biotechnol. 2019, 35, 0959-3993. [CrossRef] [PubMed]

45. Vyas, P.; Gulati, A. Organic acid production in vitro and plant growth promotion in maize under controlled environment by phosphate-solubilizing fluorescent Pseudomonas. BMC Microbol. 2009, 9, 174. [CrossRef]

46. Rasheed, A.; Eugene, C.T.; Annick, B.; Damase, P.K. Relationship between plant growth and organic acid exudates from ectomycorrhizal and non-ectomycorrhizal Pinus patula. S. Afr. J. Plant Soil 2015, 32, 183-188.

47. Krishna, P.; Reddy, M.S.; Patnaik, S.K. Aspergillus tubingensis reduces the $\mathrm{pH}$ of the bauxite residue (red mud) amended soils. Water Air Soil Pollut. 2005, 167, 201-209. [CrossRef]

48. Samson, R.A.; Noonim, P.; Meijer, M.; Houbraken, J.C.; Frisvad, J.C.; Varga, J. Diagnostic tools to identify black aspergilla. Stud. Mycol. 2007, 59, 129-145. [CrossRef]

49. Singh, S.K.; Reddy, K.R. Regulation of photosynthesis, fluorescence, stomatal conductance and water-use efficiency of cowpea (Vigna unguiculata [L.] Walp.) under drought. J. Photochem. Photobiol. B Biol. 2011, 105, 40-50. [CrossRef] [PubMed] 